\title{
Analysis of Spatial Dependence of Ore-Forming Elements Using Geostatistics and Moran Correlogram
}

\author{
Thanh Tien Nguyen
}

Faculty of Surveying, Mapping and Geographic Information, Hanoi University of Natural Resources and Environment, Bac Tu Liem, Hanoi, Vietnam.

Email:tdgis_ntthanh@163.com Tel:+84975398584

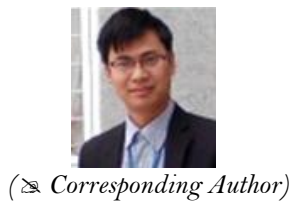

Abstract

The spatial dependence of data obtained from the geochemical prospecting process can provide useful information for evaluating mineralization potential. This study proposes two approaches to study the spatial dependence of ore-forming elements. To reduce the influence of extreme values and outliers, a semi-variogram was first used to study spatial variability and degree of spatial dependence of geochemical data using Cressie robust semi-variogram estimator. The Moran spatial correlogram was then employed to describe spatial heterogeneity and to test for the presence of spatial autocorrelation in geochemical data. The Moran's I statistics is strongly sensitive to positively skewed distribution, therefore, geochemical data were Box-Cox transformed before computing spatial correlograms. Results from a case study of $\mathrm{Ag}$ and $\mathrm{Au}$ elements in Jiurui Copper districts (southeast China) have shown that moderate spatial dependence was found for both of the $\mathrm{Au}$ and $\mathrm{Ag}$ variables, the maximum spatial variability was $20 \mathrm{~km}$ for $\mathrm{Au}$ and $10 \mathrm{~km}$ for $\mathrm{Ag}$, respectively. The degree of spatial dependence among geochemical data decreases as distances increase. These findings demonstrate that the spatial dependence of ore-forming elements can be effectively measured using geostatistics and Moran correlogram.

Keywords: Geostatistics, Cressie semi-variogram, Moran correlogram, Geochemistry, Spatial autocorrelation, Spatial dependence, Spatial variability, Jiurui Copper districts (China).

Citation | Thanh Tien Nguyen (2020). Analysis of Spatial Dependence of Ore-Forming Elements Using Geostatistics and Moran Correlogram. Asian Review of Environmental and Earth Sciences, $7(1): 47-54$

History:

Received: 30 December 2019

Revised: 4 February 2020

Accepted: 6 March 2020

Published: 10 April 2020

Licensed: This work is licensed under a Creative Commons

Attribution 3.0 License (c))

Publisher: Asian Online Journal Publishing Group
Acknowledgement: The author thanks the editor and anonymous reviewers for their constructive comments, which have greatly improved this manuscript, and Dr. Peng Gong (formerly of China University of Geosciences) manuscript, and Dr. Peng Gong (formerly of China University of Geosciences)
for providing geochemical data.

Competing Interests: The author declares that there are no conflicts of interests regarding the publication of this paper.

Funding: This study was financially supported by the Yangtze River Delta 3D Geological Survey Project (grant number 1212011220250).

Transparency: The author confirms that the manuscript is an honest, Transparency: The author confirms that the manuscript is an honest,
accurate, and transparent account of the study was reported; that no vital features of the study have been omitted; and that any discrepancies from the features of the study have been omitted
study as planned have been explained.

Ethical: This study follows all ethical practices during writing.

\section{Contents}

1. Introduction 48

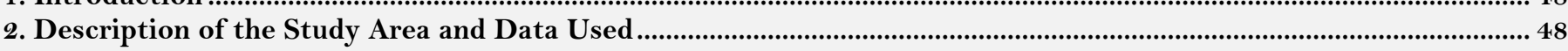

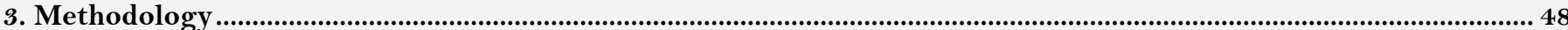

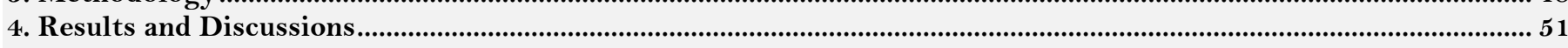

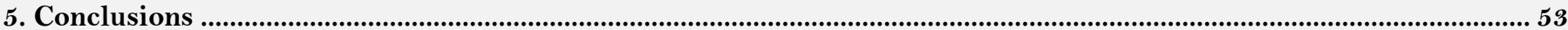

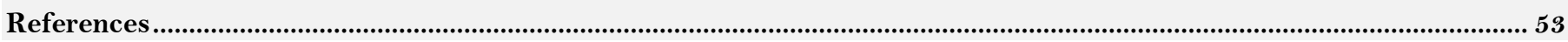




\section{Contribution of this paper to the literature}

This study proposes approaches for assessing spatial dependence of geochemical elements based on Geostatistics and Moran correlogram.

\section{Introduction}

Geochemists examine the spatial patterns of geochemical elements to understand the mechanisms and that control their spatial distribution. Therefore, an understanding of the spatial distribution of geochemical elements has important implications. The spatial structures of geochemical elements can be studied using a semi-variogram and spatial correlogram.

Classical semi-variogram was used to study spatial variability and degree of spatial dependence of the data. However, the main limitation of this approach is that the sample mean is not a stable estimator of theoretical mean. One single outlier or an extreme value can destroy this estimator completely [1]. Besides, the distribution of these elements is positively skewed, so the classical semi-variogram estimator is unbiased. For that reason, motivated by robust statistics, several types of semi-variogram estimators, based on robust estimation of scale and quantiles have been considered. A typical robust semi-variogram proposed by Armstrong and Delfiner [2] is the median of the magnitude of increments. Variants proposed include the quantile semi-variogram [3] the "Huberized" semivariogram, the jack-knifing [4] and the semi-variogram of order $1 / 2[5]$. However, the curves do not satisfy the statistical properties of a semi-variogram. Thus, a theoretical curve has to be fitted to the experimental one. Several different approaches have been proposed in the literature such as manual fitting $[6,7]$ automatic fitting including least squares using ordinary least squares [8] generalized least squares [9, 10] restricted maximum likelihood [11] maximum likelihood [10] Bayesian framework [12] MINQ estimation [13] and robust methods [14].

The spatial correlogram has been commonly used to describe spatial structures, spatial heterogeneity in quantitative ways and testing for the presence of spatial correlation in data. In addition, for multivariate data, Sokal [15] and Oden and Sokal [16] proposed to construct a spatial correlation function based on the Mantel [17] test of matrix correlation. BjØrnstad and Falck [18] proposed a spline correlogram, which provides a continuous and model-free function for the spatial covariance. The spline correlogram may be seen as a modification of the nonparametric covariance function of Hall and co-workers [19, 20].

In this study, from the above-discussion, spatial variability and degree of spatial dependence of geochemical data are assessed using Cressie robust semi-variogram. The Moran correlogram was then employed to describe spatial heterogeneity and to test for the presence of spatial autocorrelation in geochemical data.

\section{Description of the Study Area and Data Used}

\subsection{Description of the Study Area}

The Jiurui ore district mainly consists of $\mathrm{Cu}-\mathrm{Au}-\mathrm{Mo}$ deposits which are located at the transitional point of the arcuate structure of the Middle-Lower Yangtze River metallogenic belt (eastern China) [21, 22]. The developed drape fractures in the study area are surrounded by six axial parallel NEE supports, which form a closely linear drape belt. Three diggings come from this drape fracture. Fractures are mainly followed by the NWW and NEE directions and then followed by NNW and NE-NNE directions. The first two control the distribution of magmatic rocks and ore deposits in this area. The last two have a conjugate structure for the first two. Submarine sedimentation-related pyrite copper deposits are controlled by a secondary basin of the Yangtze ancient sea basin. Intermediate acidic magmatic activities-related hydrothermal deposits are controlled by the NEE direction fault structure of Yanshanian, but at the same time controlled by the inherited fault in the NWW direction.

\subsection{Data Used}

A total of 1341 composite samples representing about $5364 \mathrm{~km}^{2}$ were collected in the Jiurui ore district at a scale of 1:200.000 regional stream sediment survey. The sampling density was 1 composite sample per $4 \mathrm{~km}^{2}$. Multi-elements sediment geochemical surveys of streams were carried out in the study area including Ag, As, Au, $\mathrm{Be}, \mathrm{Cd}, \mathrm{Cu}, \mathrm{Hg}, \mathrm{Li}, \mathrm{Mn}, \mathrm{Mo}, \mathrm{Nb}, \mathrm{Pb}, \mathrm{Sb}, \mathrm{Sn}, \mathrm{Th}, \mathrm{V}, \mathrm{W}, \mathrm{Y}, \mathrm{Zn}, \mathrm{Al}_{2} \mathrm{O}_{3}, \mathrm{CaO}, \mathrm{K}_{2} \mathrm{O}, \mathrm{Na}_{2} \mathrm{O}$, etc., in which $\mathrm{Ag}$ and $\mathrm{Au}$ are ore-forming elements [23]. In addition, three geochemical associations of elements also caused the anomalous area in the study areas [24]. There are two metallogenenic series in the study area with a total of 13 known ore deposits.

\section{Methodology}

\subsection{Cressie Semi-Variogram}

Let consider a spatial stochastic process $\{\mathrm{Z}(\mathrm{x}): \mathrm{x} \in D\}$, where $D$ is a fixed subset of $\mathbb{R}^{d}, d \geq 1$. Assume that this stochastic process is ergodic and also satisfies the hypothesis of intrinsic stationarity, the expected (E) and variance (Var) values of $\mathrm{Z}(\mathrm{x})$ are given by Hoang, et al. [25] in Equations 1 and 2:

$$
\begin{gathered}
\mathrm{E}(Z(\mathrm{x}))=\mu=\mathrm{constant}, \quad \forall \mathrm{x} \in D \\
\operatorname{Var}[Z(\mathrm{x}+\mathrm{h})-Z(\mathrm{x})]=2 \gamma(h), \quad \forall \mathrm{x}, \mathrm{x}+\mathrm{h} \in D
\end{gathered}
$$

where: $Z(\mathrm{x})$ is the value of observed variable and $2 \gamma(h)$ is the semi-variogram of $Z(\mathrm{x})$ at lag $\mathrm{h}$. This is a very simple model that can be used in practice after detrending data [26] or in several cases even used directly. In this study, the semi-variogram of order $1 / 2$ estimator will be used to estimate the robust semi-variogram. Let $\left\{\mathrm{Z}\left(\mathrm{x}_{1}\right), \mathrm{Z}\left(\mathrm{x}_{2}\right), \ldots, \mathrm{Z}\left(\mathrm{x}_{\mathrm{n}}\right)\right\}$ be a sample of such a spatial stochastic process. The Cressie robust semi-variogram estimator is expressed as the following equation:

$$
2 \hat{\gamma}(h)=\left[\frac{1}{\mathrm{~N}_{\mathrm{h}}} \sum_{(\mathrm{i}, \mathrm{j}) \mid d_{\mathrm{ij}} \approx d}^{\mathrm{N}(\mathrm{h})}\left|Z\left(\mathrm{x}_{\mathrm{i}}\right)-Z\left(\mathrm{x}_{\mathrm{j}}\right)\right|^{1 / 2}\right]^{4} /\left(0.457+\frac{0.494}{\mathrm{~N}_{\mathrm{h}}}\right) \quad \forall \mathrm{h} \in \mathbb{R}^{d}
$$


where: $\mathrm{N}(\mathrm{h})=\left\{\left(\mathrm{x}_{\mathrm{i}}, \mathrm{x}_{\mathrm{j}}\right): \mathrm{x}_{\mathrm{i}}-\mathrm{x}_{\mathrm{j}}=\mathrm{h} ; \mathrm{i}, \mathrm{j}=1, \ldots, \mathrm{n}\right\}, Z\left(\mathrm{x}_{\mathrm{i}}\right)$ and $Z\left(\mathrm{x}_{\mathrm{j}}\right)$ are values of an observed variable at locations $i$ and $j, d_{\mathrm{ij}} \approx d$ means that distances may be grouped into distance classes, placing in class $d$ the individual distances $d_{\mathrm{ij}}$ that are approximately equal to $d$. The denominator of Equation 3 corrects for bias under gausianity, and:

$$
2 \hat{\gamma}(\mathrm{h})=\left[\operatorname{med}\left\{\left|Z\left(\mathrm{x}_{\mathrm{i}}\right)-Z\left(\mathrm{x}_{\mathrm{j}}\right)\right|^{1 / 2}:\left(\mathrm{x}_{\mathrm{i}}, \mathrm{x}_{\mathrm{j}}\right) \in \mathrm{N}(\mathrm{h})\right\}\right]^{4} \frac{1}{\mathrm{~B}(\mathrm{~h})} \quad \forall \mathrm{h} \in \mathbb{R}^{d}
$$

where: $Z\left(\mathrm{x}_{\mathrm{i}}\right)$ and $Z\left(\mathrm{x}_{\mathrm{j}}\right)$ are defined as in Equation 3, med $\{$.$\} denotes the median of the sequence \left\{\mid Z\left(\mathrm{x}_{\mathrm{i}}\right)-\right.$ $\left.\left.Z\left(\mathrm{x}_{\mathrm{j}}\right)\right|^{1 / 2}\right\}$ and $\mathrm{B}(\mathrm{h})$ corrects for bias [assymptotically, $\left.\mathrm{B}(\mathrm{h})=0.457\right]$. The reasoning behind Equation 3 is that, for Gaussian data, $\left[Z\left(\mathrm{x}_{\mathrm{i}}\right)-Z\left(\mathrm{x}_{\mathrm{j}}\right)\right]^{2}$ is a chi-squared random variable on one degree of freedom. The power transformation that makes this most Gaussian-like is the fourth root [27] namely $\left|Z\left(\mathrm{x}_{\mathrm{i}}\right)-Z\left(\mathrm{x}_{\mathrm{j}}\right)\right|^{1 / 2}$, the square root of the absolute difference. Thus, various location estimators can be applied to $\left\{\left[Z\left(\mathrm{x}_{\mathrm{i}}\right)-Z\left(\mathrm{x}_{\mathrm{j}}\right)\right]^{2}:\left(\mathrm{x}_{\mathrm{i}}, \mathrm{x}_{\mathrm{j}}\right) \in\right.$ $\mathrm{N}(\mathrm{h})\}$, which, when untransformed and normalized for bias, yield robust semi-variogram estimators.

A model must be fitted to the sample semi-variogram. The model will provide values of semi-variance for all the intermediate distances. The most commonly used models are the spherical model, exponential model, Gaussian model, hole effect model, linear model, pure nugget effect model, etc as shown in Figure 1.

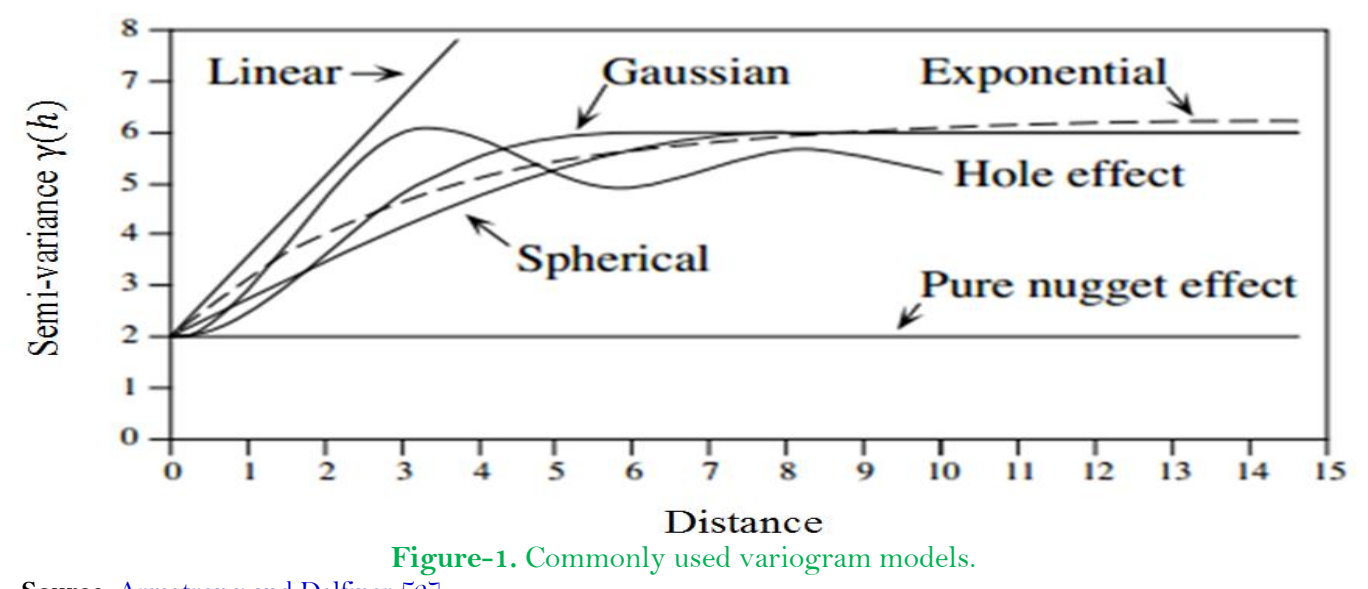

Source: Armstrong and Delfiner [2].

Semi-variograms may be used to determine whether anisotropy is present in the data set. They may also be used to describe anisotropic surfaces or to account for anisotropy in kriging interpolation [24]. A direction of space is first chosen (i.e. an angle $\theta$ ) and a search is then launched for the pairs of sampling points that are within a given distance class $h$ in that given direction. There may be only a few such pairs perfectly aligned in the aiming direction $\theta$, or even none at all, in particular when sampling is not regularly spaced on the map. More pairs of points can usually be found by looking within a small neighborhood around the aiming line as shown in Figure 2. The neighborhood is determined by an angular tolerance parameter $\varphi$ and a parameter $\kappa$ that sets the tolerance for distance classes along the aiming line. For each observed point $\emptyset_{h}$ in turn, one looks for other points $\emptyset_{i}$ that are at distance $h \pm \kappa$ from it. All points found within the search-window are paired with the reference point $\emptyset_{h}$ included in the calculation of semi-variance for distance class $h$ [24]. In Figure 2 , from an observed study site $\emptyset_{1}$, an aiming line is drawn in the direction determined by angle $\theta$, the angular tolerance parameter $\varphi$ determines the search zone (grey) laterally whereas parameter $\kappa$ sets the tolerance along the aiming line for each distance class $h$.

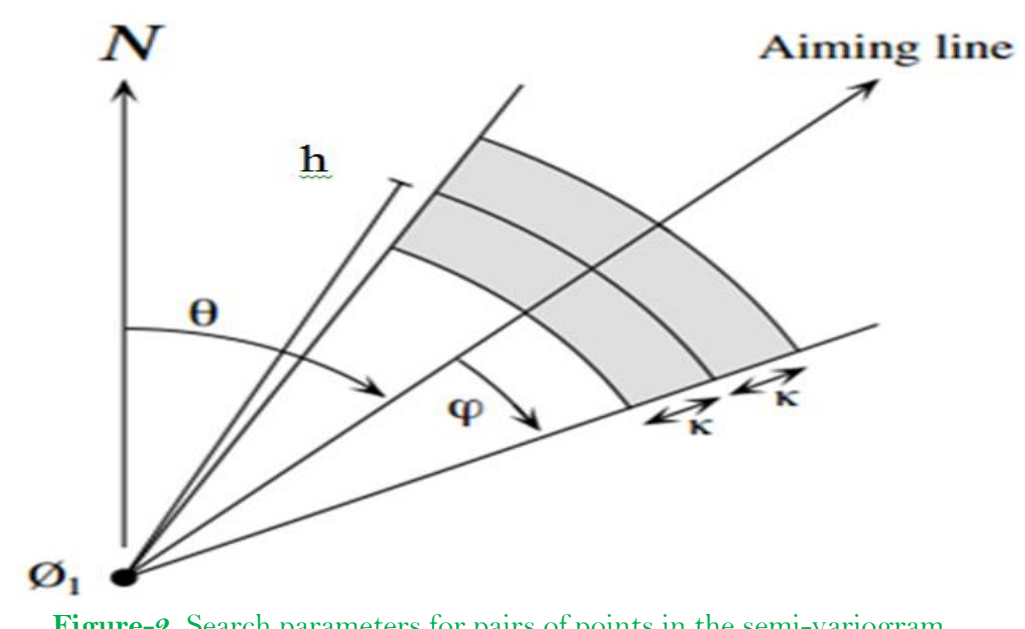

Figure-2. Search parameters for pairs of points in the semi-variogram. Source: Legendre and Legendre [24].

Hoang, et al. [25] indicated that the distance at which the variance levels off is referred to as the range (or maximum spatial variability), $a$; beyond that distance, the sampling units are not spatially correlated. The parameter for the nugget effect is $C_{0}$ and the spatially structured component is represented by $C_{1}$; the sill, $C$, is equal to $C_{0}+C_{1}$ Figure 3. Spatial variability can be investigated using the semi-variogram and the relative nugget effect, which is the ratio of the nugget to total semivariance expressed as percentage, $C_{0} /\left(C_{0}+C_{1}\right)[24]$. A ratio of 
less than 25\% indicates strong spatial dependence, between $25 \%$ and $75 \%$ indicates moderate spatial dependence, and greater than $75 \%$ indicates weak spatial dependence [1].

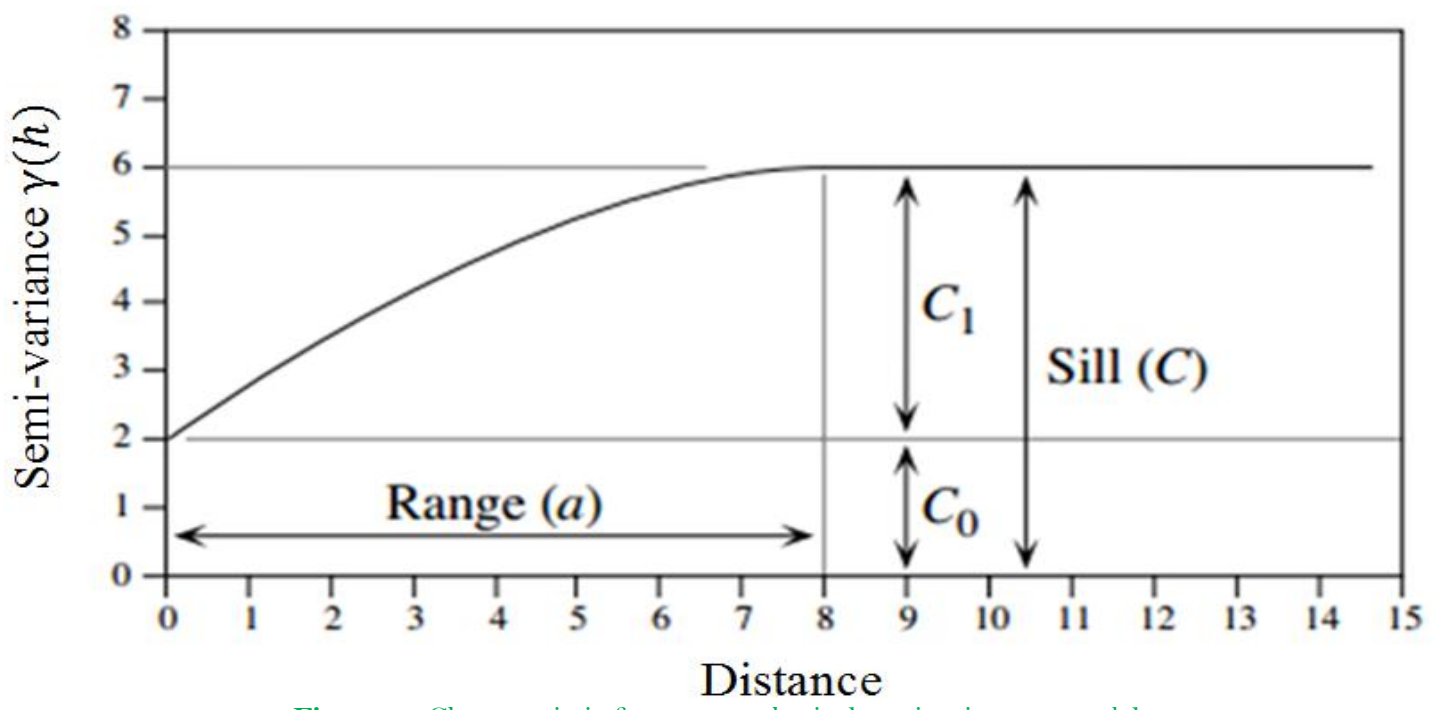

Figure-3. Characteristic features a spherical semivariogram model.

Source: Legendre and Legendre [24], Hoang, et al. [25].

\subsection{Moran Correlogram}

Spatial correlation of a uni-variate can be measured using spatial correlation statistics such as Moran's $I$ or Geary's $C$ statistics [27]. The Moran's I statistics seems to be the most popularly used [1], that is given:

$$
I(d)=\frac{\mathrm{N}}{\mathrm{S}_{0}} \frac{\sum_{\mathrm{i}=1}^{\mathrm{N}} \sum_{\mathrm{j}=1}^{\mathrm{N}} \mathrm{W}_{\mathrm{ij}}\left(\mathrm{x}_{\mathrm{i}}-\overline{\mathrm{x}}\right)\left(\mathrm{x}_{\mathrm{j}}-\overline{\mathrm{x}}\right)}{\sum_{\mathrm{i}=1}^{\mathrm{N}}\left(\mathrm{x}_{\mathrm{i}}-\overline{\mathrm{x}}\right)^{2}}
$$

where: $x_{i}$ and $x_{j}$ are the values of an observed variable at sites $i$ and $j, d$ is the distance class considered in the calculation, $S_{0}$ is the sum of the weights $W_{i j}$, given $\mathrm{S}_{0}=\sum_{\mathrm{i}=1}^{\mathrm{N}} \sum_{\mathrm{j}=\mathrm{i}}^{\mathrm{N}} \mathrm{W}_{\mathrm{ij}}, \bar{x}$ is the sample mean of an observed variable, given by: $\overline{\mathrm{x}}=\sum_{\mathrm{i}=1}^{\mathrm{N}} \frac{\mathrm{x}_{\mathrm{i}}}{\mathrm{N}}, N$ stands for the number of observations with $\mathrm{W}_{\mathrm{ij}}$ is spatial weight matrix for a given distance $d$ and $\mathrm{d}_{\mathrm{ij}}$ is the distance between the observations $i$ and $j$.

Spatial correlation coefficients can be tested for significance. The tests require that the condition of secondorder stationarity (or a relaxed form of stationarity, intrinsic stationarity). Cliff and Ord [27] describe how to compute confidence intervals and test the significance of spatial correlation coefficients. For any normally distributed statistic Stat, a confidence interval at significance level $\alpha$ is obtained as follows:

$$
\operatorname{Pr}\left(\text { Stat }-\mathrm{z}_{\alpha / 2} \sqrt{\operatorname{Var}(\text { Stat })}<\text { Stat }<\text { Stat }+\mathrm{z}_{\alpha / 2} \sqrt{\operatorname{Var}(\text { Stat })}\right)=1-\alpha
$$

In Equation 6, for significance testing with large samples, a one-tailed critical value $S t a t_{\alpha}$ at significance level $\alpha$ is obtained as follows:

$$
\text { Stat }_{\alpha}=\mathrm{z}_{\alpha} \sqrt{\operatorname{Var(Stat)}}+\text { Expected value of Stat under } \mathrm{H}_{0}
$$

where: value $z_{\alpha / 2}$ or $z_{\alpha}$ in Equation 6 and 7 is found in the table of standard normal deviates.

It is possible to use this approach because Moran's $I$ is asymptotically normally distributed for data sets of moderate to large sizes [27]. Under the hypothesis $\left(\mathrm{H}_{0}\right)$ of the random spatial distribution of the observed values $\mathrm{x}_{\mathrm{i}}$, the expected values (E) of Moran's $I$ statistic is given by the following Equation:

where: $\mathrm{N}$ is defined as in Equation 5.

$$
\mathrm{E}(I)=\frac{-1}{\mathrm{~N}-1}
$$

It can be seen that, under the null hypothesis, $\mathrm{E}(I)$ approaches $\mathrm{O}$ as $\mathrm{n}$ increases. The variance is computed using Equation 9 under a randomization assumption, which simply states that, under $H_{0}$, the observations $x_{i}$ are independent of their positions in space (second-order stationarity assumption) and, thus, are exchangeable [27].

$$
=\frac{\operatorname{Var}(I)=\mathrm{E}\left(\mathrm{I}^{2}\right)-[\mathrm{E}(I)]^{2}}{\left.2 \mathrm{n}+3) \mathrm{~S}_{1}-\mathrm{nS}_{2}+3 \mathrm{~W}^{2}\right]-\mathrm{b}_{2}\left[\left(\mathrm{n}^{2}-\mathrm{n}\right) \mathrm{S}_{1}-2 \mathrm{nS}_{2}+6 \mathrm{~W}^{2}\right]}-\left(\frac{1}{\mathrm{~N}-1}\right)^{2}
$$

In Equation $9, \mathbf{S}_{1}, \mathbf{S}_{2}$, and $\mathbf{b}_{2}$ can be obtained by the following Equations:

$$
\begin{gathered}
\mathrm{S}_{1}=\frac{1}{2} \sum_{\mathrm{i}=1}^{\mathrm{n}} \sum_{\mathrm{j}=1}^{\mathrm{n}}\left(\mathrm{W}_{\mathrm{ij}}+\mathrm{W}_{\mathrm{ji}}\right)^{2} \\
\mathrm{~S}_{2}=\frac{1}{2} \sum_{\mathrm{i}=1}^{\mathrm{N}}\left(\sum_{\mathrm{j}=1}^{\mathrm{N}}\left(\mathrm{W}_{\mathrm{ij}}+\sum_{\mathrm{j}=1}^{\mathrm{n}} \mathrm{W}_{\mathrm{ij}}\right)^{2},\right. \\
\mathrm{b}_{2}=\mathrm{n} \sum_{\mathrm{i}=1}^{\mathrm{n}}\left(\mathrm{x}_{\mathrm{i}}-\overline{\mathrm{x}}\right)^{4} /\left[\sum_{\mathrm{i}=1}^{\mathrm{n}}\left(\mathrm{x}_{\mathrm{i}}-\overline{\mathrm{x}}\right)^{2}\right]^{2}
\end{gathered}
$$

where: $x_{i}, x_{j}, \mathrm{~W}_{\mathrm{ij}}$ and $\mathrm{W}_{\mathrm{ji}}$ are defined as in Equation 5 , and $\mathrm{n}$ is number of observations.

In most cases, tests of spatial correlation are one-tailed. Geological variables are usually positively correlated at short distances. To carry out an approximate test of significance, a value of $\alpha$ is selected (e.g $\alpha=0.05$ ) and find $z_{\alpha}$ in a table of the standard normal distribution $\left(\mathrm{e} . \mathrm{g} z_{0.05}=+1.6452\right)$. Critical values are found as Equation 7 with a 
correction factor that becomes important when $n$ is small: $I_{\alpha}=\mathrm{z}_{\alpha} \sqrt{\operatorname{Var}(I)}-\mathrm{k}_{\alpha}(\mathrm{n}-1)^{-1}$ in all cases, using the value in the upper tail of the $z$ distribution when testing for positive spatial correlation (e.g $z_{0.05}=+1.6452$, and the value in the lower tail in the opposite case (e.g $\left.z_{0.05}=-1.6452\right)$.

The value taken by the correction factor $k_{\alpha}$ depends on the values of $n$ and $S_{0}$. If $4(\mathrm{n}-\sqrt{\mathrm{n}})<S_{0} \leq$ $4(2 \mathrm{n}-3 \sqrt{\mathrm{n}}+1)$, then $k_{\alpha}=\sqrt{10 \alpha}$; otherwise, $k_{\alpha}=1$. If the test is two-tailed, use $\alpha^{*}=\alpha / 2$ to find $z_{\alpha^{*}}$ and $k_{\alpha^{*}}$ before computing critical values. The corrections are based upon simulations reported by Cliff and Ord [27]. Other formulas can be found in Cliff and Ord [27] for conducting a test under the assumption of normality, where one assumes that the result of $x_{i}^{\prime}$ from independent draws from a normal population. It has been suggested that when $n$ is very small, tests of I should be conducted by permutation [1, 24].

\section{Results and Discussions}

\subsection{Spatial Variability Analysis}

Data from Figure 4-a and 4-b demonstrates that the semivariances for the variable Au for the omni-directional semi-variogram and directional semi-variograms in four different directions. The experimental semi-variogram shows a big nugget effect, $C_{0}$, which accounts for about $57 \%$ of the total sill $C_{0}+C_{1}$ after fitted with a theoretical model as shown in Table 1. A ratio of nugget to total semivariance of $57 \%$ between $25 \%$ and $75 \%$ indicates moderate spatial dependence. The nugget effect shows a small-scale variation in the data due to the problem of sampling unintensiveness Figure 4-a. However, there was a slightly significant difference in the variation according to four different directions. The directional semi-variograms displays the same sill. All curves start at about the same point. All curves of directional variograms of Au almost flatten out at $20 \mathrm{~km}$ and show small different total variances Figure 4-b. Similarly, the hole effect appears due to the presence of one or more mineral occurrences.

Table-1. Summary table of geostatistical parameters of Au and Ag ore-forming elements.

\begin{tabular}{c|c|c|c|c|c|c}
\hline Elements & Direction & $\begin{array}{c}\text { Nugget } \\
\text { effect } \\
\left(\boldsymbol{C}_{\mathbf{0}}\right)\end{array}$ & $\begin{array}{c}\text { Spatially } \\
\text { structure } \\
\left(\mathbf{C}_{\mathbf{1}}\right)\end{array}$ & $\begin{array}{c}\text { Sill } \\
\left(\mathbf{C}_{\mathbf{0}}+\mathbf{C}_{\mathbf{1}}\right)\end{array}$ & $\begin{array}{c}\text { Spatial range } \\
(\mathbf{k m})(\boldsymbol{a})\end{array}$ & $\begin{array}{c}\text { Relative } \\
\text { nugget effect } \\
\mathbf{C}_{\mathbf{0}} /\left(\mathbf{C}_{\mathbf{0}}+\mathbf{C}_{\mathbf{1}}\right)\end{array}$ \\
\hline $\mathrm{Au}$ & $\mathrm{omni}$ & 0.21 & 0.16 & 0.37 & 35.9 & $57 \%$ \\
\hline $\mathrm{Ag}$ & $\mathrm{omni}$ & 0.00025 & 0.00027 & 0.00052 & 15.5 & $48 \%$ \\
\hline
\end{tabular}
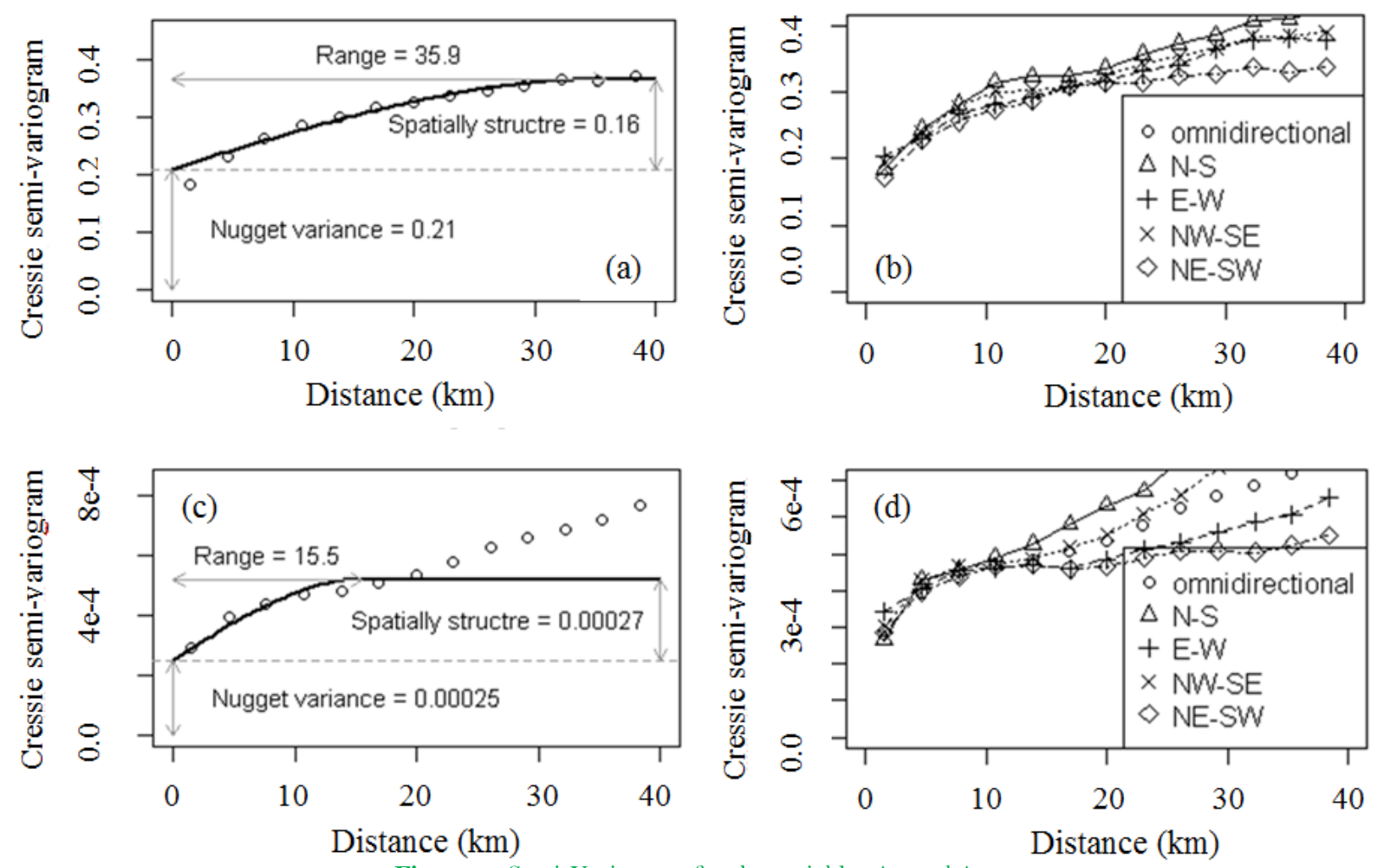

Data from Figures 4-c and 4-d illustrates the semivariances for the variable $\mathrm{Ag}$ for the omni-directional semivariogram additional to four directional variograms in different directions. Experimental omni-directional variogram shows a moderate nugget effect, $C_{0}$, which accounts for about $48 \%$ of the total sill $C_{0}+C_{1}$ after fitted with a theoretical model Table 1 . A ratio of nugget to total semivariance of $48 \%$ between $25 \%$ and $75 \%$ indicates moderate spatial dependence. The nugget effect of the variable $\mathrm{Ag}$ also shows a small-scale variation in the data due to the problem of sampling unintensiveness. All curves start at about the same point and they flatten out at about $14 \mathrm{~km}$. The sampling units are not spatially correlated with no spatial dependence in the variable Ag when the distance beyond $15.5 \mathrm{~km}$ Figures 4-c. Directional semi-variograms vary strongly with directions and big different total variance when the distance is more than $14 \mathrm{~km}$, especially on the northeast-southwest, northwestsoutheast and north-south directions Figure 4-d. It can be inferred that the hole effect appears due to the presence of one or more mineral occurrences. It reflects a tendency for high values to be systematically surrounded by low values and vice versa. 


\subsection{Spatial Structure Analysis}

The surfaces in Figures 5-a and 5-c were made from 1341 sampling points across the surface using a regular $49 \times 38$ grid $(2 \times 2 \mathrm{~km}$ in a grid). The "height" was noted at each sampling point. The distances among points were divided into 60 distance classes. Testing the significance of correlograms with each distance class by randomization test with 500 times of permutation at the $\alpha=0.05$ level. Spatial correlograms were computed using the 'raw' data. However, the distribution of the "raw" data is strongly right-skewed due to many extreme values and outliers. Besides, Moran's I statistics is very sensitive to extreme values and asymmetry in the data distributions. To easily reach significance in statistical tests, the data were Box-Cox transformed to compute Moran's $I$ correlograms. Moran's I coefficients at distances ranging from $2 \mathrm{~km}$ to $34.8 \mathrm{~km}$ and their p-values of the Au and Ag variables are summarised in Table 2.

\begin{tabular}{|c|c|c|c|c|c|c|c|c|}
\hline \multirow{3}{*}{$\begin{array}{l}\text { Distance } \\
\quad(\mathbf{k m})\end{array}$} & \multicolumn{4}{|c|}{$\mathrm{Au}$} & \multicolumn{4}{|c|}{$\mathrm{Ag}$} \\
\hline & \multicolumn{2}{|c|}{ Raw data } & \multicolumn{2}{|c|}{ Box-Cox transformed data } & \multicolumn{2}{|c|}{ Raw data } & \multicolumn{2}{|c|}{$\begin{array}{c}\text { Box-Cox transformed } \\
\text { data }\end{array}$} \\
\hline & $\begin{array}{c}\text { Moran's } I \\
\text { coefficient }\end{array}$ & $p$-value & $\begin{array}{c}\text { Moran's I } \\
\text { coefficients }\end{array}$ & $p$-value & $\begin{array}{l}\text { Moran's } I \\
\text { coefficient }\end{array}$ & $p$-value & $\begin{array}{l}\text { Moran's } I \\
\text { coefficient }\end{array}$ & $p$-value \\
\hline 2.0 & 0.029 & 0.018 & 0.41 & 0.002 & 0.11 & 0.008 & 0.54 & 0.002 \\
\hline 3.4 & 0.021 & 0.032 & 0.35 & 0.002 & 0.06 & 0.008 & 0.40 & 0.002 \\
\hline 5.1 & 0.026 & 0.016 & 0.30 & 0.002 & 0.04 & 0.006 & 0.30 & 0.002 \\
\hline 7.0 & 0.011 & 0.05 & 0.24 & 0.002 & 0.01 & 0.038 & 0.22 & 0.002 \\
\hline 9.1 & 0.007 & 0.05 & 0.20 & 0.002 & 0.00 & 0.144 & 0.16 & 0.002 \\
\hline 11.1 & 0.005 & 0.126 & 0.17 & 0.002 & 0.00 & 0.118 & 0.13 & 0.002 \\
\hline 12.9 & 0.009 & 0.022 & 0.15 & 0.002 & 0.00 & 0.367 & 0.11 & 0.002 \\
\hline 14.8 & 0.005 & 0.068 & 0.13 & 0.002 & 0.00 & 0.140 & 0.10 & 0.002 \\
\hline 16.9 & 0.005 & 0.09 & 0.12 & 0.002 & 0.00 & 0.204 & 0.09 & 0.002 \\
\hline 19.0 & 0.003 & 0.116 & 0.10 & 0.002 & 0.01 & 0.040 & 0.07 & 0.002 \\
\hline 21.0 & 0.005 & 0.066 & 0.09 & 0.002 & 0.00 & 0.104 & 0.06 & 0.002 \\
\hline 22.8 & 0.005 & 0.076 & 0.07 & 0.002 & 0.01 & 0.036 & 0.05 & 0.002 \\
\hline 24.9 & 0.016 & 0.004 & 0.06 & 0.002 & 0.00 & 0.463 & 0.03 & 0.002 \\
\hline 26.9 & 0.003 & 0.144 & 0.04 & 0.002 & 0.00 & 0.154 & 0.03 & 0.002 \\
\hline 29.0 & -0.003 & 0.246 & 0.00 & 0.218 & 0.00 & 0.126 & 0.04 & 0.002 \\
\hline 30.9 & 0.007 & 0.038 & 0.00 & 0.210 & -0.01 & 0.036 & 0.04 & 0.002 \\
\hline 32.9 & 0.000 & 0.253 & -0.01 & 0.092 & 0.00 & 0.122 & 0.03 & 0.002 \\
\hline 34.8 & 0.001 & 0.257 & -0.01 & 0.162 & -0.01 & 0.034 & 0.02 & 0.002 \\
\hline
\end{tabular}

Data from Moran's $I$ correlogram of the Au variable in Figure 5-b and Table 2 demonstrate that the first spatial correlation coefficient of 0.029 indicates a weak positive spatial correlation in the first distance class for the 'raw' data. The second positive and significant spatial correlation coefficient of 0.021 occurs at distances ranging from $2 \mathrm{~km}$ to $3.4 \mathrm{~km}$. The next positive spatial correlation coefficient was detected at distances from $11.1 \mathrm{~km}$ to $12.9 \mathrm{~km}$. The last positive and significant correlation was found with a coefficient of 0.016 . There was no spatial correlation (spatial dependence) at distances ranging from $2.0 \mathrm{~km}$ to $3.4 \mathrm{~km}$, from 7.0 to $11.1 \mathrm{~km}$, and from $12.9 \mathrm{~km}$ to $22.8 \mathrm{~km}$, respectively. Besides, negative and significant spatial correlation was detected at distances ranging from $50 \mathrm{~km}$ to $70 \mathrm{~km}$.
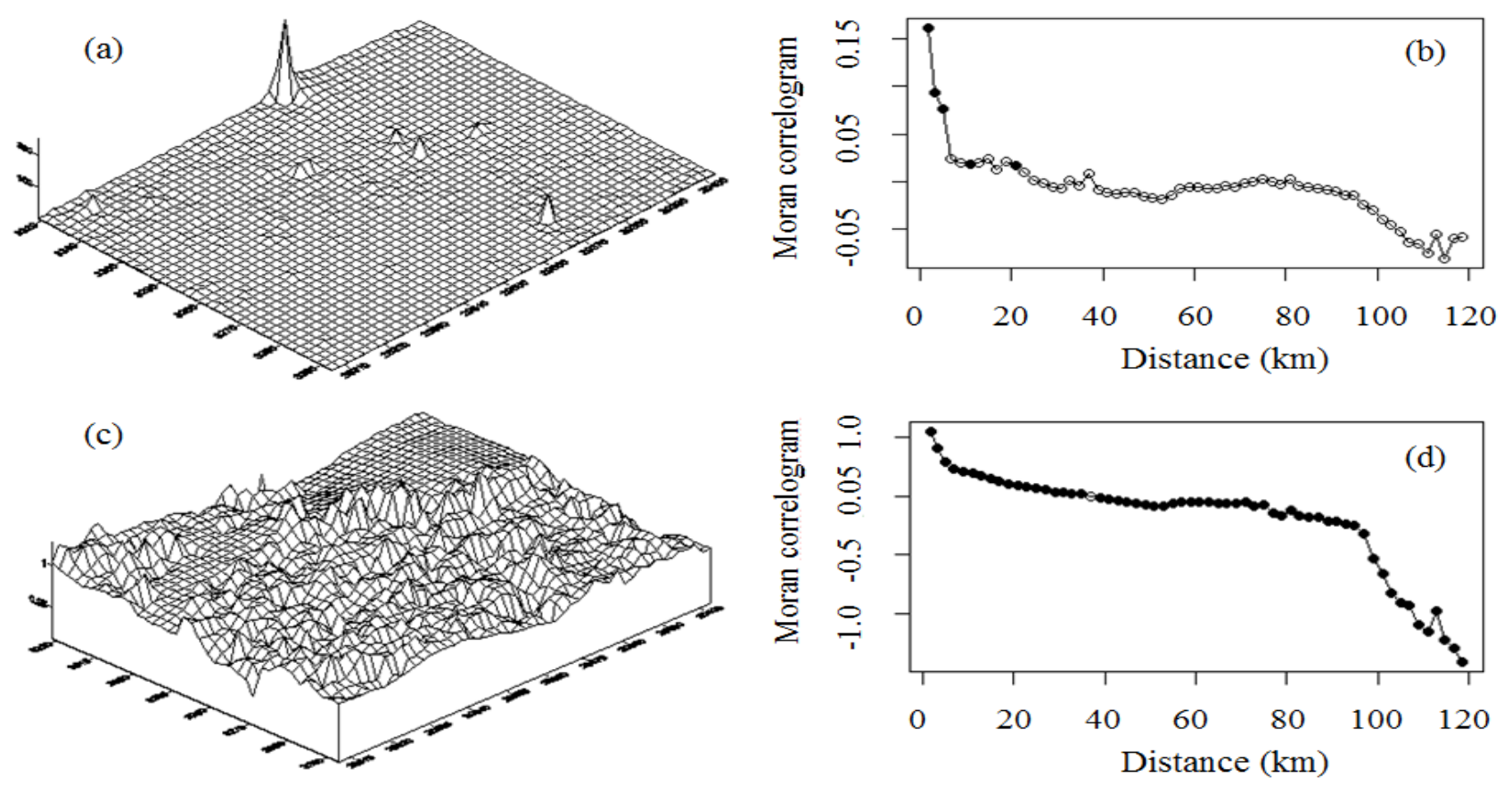

Figure-5. The surface of Au: raw data (a) and of transformed data (c) and Moran correlogram: raw data (b) and transformed data (c).

The surface and Moran correlogram for Box-Cox transformed data of the variable Au shown in Figures 5-c and 5-d. Data from Table 2 demonstrates that the first spatial correlation coefficient of 0.41 was bigger than that of 'raw' data. This trend is similar to the next spatial correlation coefficients with values of $0.35,0.30,0.24$, and 0.20 at distances ranging from $3.4 \mathrm{~km}$ to $9.1 \mathrm{~km}$. Spatial correlation coefficients are gradually reduced as distances increase. Positive and significant correlation coefficients were also found at distances below $26.9 \mathrm{~km}$, whereas no 
spatial correlation was detected at distances ranging from $29 \mathrm{~km}$ to $34.8 \mathrm{~km}$. Negative and significant spatial correlation at distances from $32.9 \mathrm{~km}$ to $76 \mathrm{~km}$.

Data from Moran correlogram for the Ag element in Figure 6-b shows that three positive and significant spatial correlation coefficients were found at distances ranging from $2 \mathrm{~km}$ to $5.1 \mathrm{~km}$, whereas, no spatial correlation was found at distances ranging from $5.1 \mathrm{~km}$ to $34.8 \mathrm{~km}$. In addition, there existed negative and significant spatial correlation coefficients at distances ranging from $34.8 \mathrm{~km}$ to $44 \mathrm{~km}$ and no spatial correlation at distances above 44 $\mathrm{km}$.

The surface and Moran's correlogram for Box-Cox transformed data of the variable Ag in Figures 6-c and 6-d show similarities with those obtained from the Au variable, the first spatial correlation coefficient of 0.54 was much bigger than that of 'raw' data and similarly for the next spatial correlation coefficients, $0.40,0.30,0.22,0.16$ at distances ranging from $3.4 \mathrm{~km}$ to $9.1 \mathrm{~km}$. Spatial correlation coefficients were also gradually reduced as distances increase. Spatial correlogram in Figure 6-d show that there existed positive and significant correlation at distances below $36.9 \mathrm{~km}$ and strong spatial correlation at distances below $12.9 \mathrm{~km}$, weak spatial correlation at distances between $12.9 \mathrm{~km}$ and $36.9 \mathrm{~km}$; no spatial correlation at distances from $30.9 \mathrm{~km}$ to $36.9 \mathrm{~km}$, and negative and significant at distances from $36.9 \mathrm{~km}$ to $74 \mathrm{~km}$.
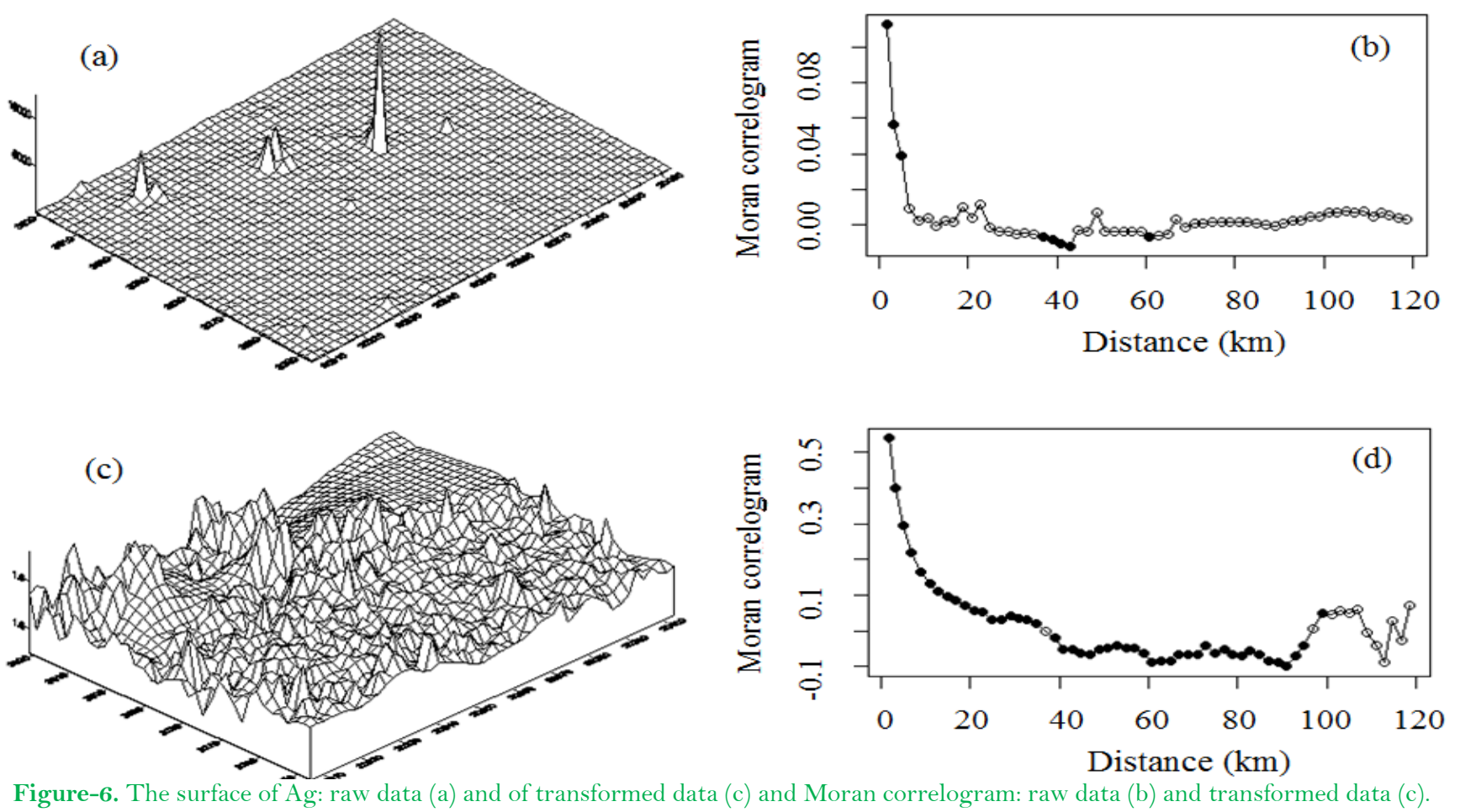

\section{Conclusions}

In this study, Cressie robust semi-variogram and Moran correlogram have been employed to study the spatial dependence of ore-forming elements. Cressie robust semi-variogram was first used to study spatial variability and identify the level of spatial dependence in data. The Moran spatial correlogram was then applied to describe spatial structure and spatial heterogeneity. Results from a case study of $\mathrm{Ag}$ and $\mathrm{Au}$ elements in Jiurui Copper districts have shown that moderate spatial dependence was found for both of the Au and Ag variables, the maximum spatial variability was $20 \mathrm{~km}$ for $\mathrm{Au}$ and $10 \mathrm{~km}$ for Ag, respectively. An important conclusion can be made is that the results were strongly affected by the existence of extreme values and outliers, so it is suggested that the raw data should be transformed. In addition, the precision of the spatial correlogram depends on spatial classes (distances), whereas, the computational complexity is remarkably increased when spatial classes are decreased.

\section{References}

[1] L. Anselin, "Local indicators of spatial association-LISA," Geographical Analysis, vol. 27, pp. 93-115, 1995. Available at: https://doi.org/10.1111/j.1538-4632.1995.tbo0338.x.

[2] M. Armstrong and P. Delfiner, Towards a more robust variogram: A case study on coal. Paris: Springer, 1980. [3] O. N. Bjornstad and W. Falck, "Nonparametric spatial covariance functions: Estimation and testing," Environmental and Ecological
Statistics, vol. 8, pp. 53-70, 2001.

[4] C. Chung, "Use of the jackknife method to estimate autocorrelation functions (or variograms), In Geostatistics for Natural Resources Characterization," ed Dordrecht: Springer, 1984, pp. 55-69.

[5] N. Cressie and D. M. Hawkins, "Robust estimation of the variogram: I," Journal of the International Association for Mathematical Geology, vol. 12, pp. 115-125, 1980.

$[6] \quad$ M. Hohn, "Geostatistics and petroleum geology," ed The Netherlands: Springer Science \& Business Media, 1998, pp. 100-138.
$[7] \quad$ R. A. Olea, "Geostatistics for engineers and earth scientists," ed The Netherlands: Springer Science \& Business Media, 2012, pp. $10-40$.

[8] M. David, "Geostatistical ore reserve estimation," ed The Netherlands: Elsevier, 2012, pp. 73-90.

[9] N. Cressie, "Fitting variogram models by weighted least squares," Journal of the international Association for mathematical Geology, vol. 17, pp. 563-586, 1985. Available at: https://doi.org/10.1007/bfo 1032109.

[10] N. Cressie, "Statistics for spatial data," ed New York: John Wiley \& Sons, 2015, pp. 27-104.

[11] M. G. Kenward and J. H. Roger, "Small sample inference for fixed effects from restricted maximum likelihood," Biometrics, vol. 53, pp. 983-997, 1997. Available at: https://doi.org/10.2307/2533558.

[12] T. Egeland, P. Mostad, N. Hjort, A. Kraggerud, and P. Biver, "Variogram estimation in a Bayesian framework," Geostatistics Wollongong, vol. 96, pp. 223-233, 1997.

[13] C. R. Rao and J. Kleffe, "Estimation of variance components,Statistics and probability." vol. 3, ed Amsterdam: North-Holland, 1988, p. 370 .

[14] W. H. Fellner, "Robust estimation of variance components," Technometrics, vol. 28, pp. 51-60, 1986.

[15] R. R. Sokal, "Spatial data analysis and historical processes," Data Analysis and Informatics vol. 4, pp. $29-43,1986$. 
[16] N. L. Oden and R. R. Sokal, "Directional autocorrelation: An extension of spatial correlograms to two dimensions," Systematic Zoology, vol. 35, pp. 608-617, 1986. Available at: https://doi.org/10.2307/2413120.

[17] N. Mantel, "The detection of disease clustering and a generalized regression approach," Cancer Research, vol. 27, pp. 209-220, 1967.

[18] O. N. BjØrnstad and W. Falck, "Nonparametric spatial covariance functions: Estimation and testing," Environmental and Ecological Statistics, vol. 8, pp. 53-70, 2001.

[19] P. Hall, N. I. Fisher, and B. Hoffmann, "On the nonparametric estimation of covariance functions," The Annals of Statistics, vol. 22, pp. $2115-2134,1994$. Available at: https://doi.org/10.1214/aos/1176325774.

[20] P. Hall and P. Patil, "Properties of nonparametric estimators of autocovariance for stationary random fields," Probability Theory and Related Fields, vol. 99, pp. 399-424, 1994. Available at: https://doi.org/10.1007/bfo 1199899.

[21] T. T. Nguyen, D. T. Vu, L. H. Trinh, and T. L. H. Nguyen, "Spatial cluster and outlier identification of geochemical association of eements: A case study in Juirui Copper Mining Area," Bulletin Of The Mineral Research and Exploration, vol. 53, pp. 159-167, 2016. Available at: https://doi.org/10.19111/bmre.01695.

[22] T. T. Nguyen and T. D. Vu, "Identification of multivariate geochemical anomalies using spatial autocorrelation analysis and robust statistics," Ore Geology Reviews, vol. 111, pp. 1-16, 2019.

[23] T. T. Nguyen, "Use of Moran's I and robust statistics to separate geochemical anomalies in Jiurui area (Southeast China)," Bulletin of the Mineral Research and Exploration, vol. 156, pp. 22-44, 2018.

[24] P. Legendre and L. F. Legendre, Numerical ecology. The Netherlands: Elsevier, 2012.

[25] H. A. Hoang, T. D. Vu, and T. T. Nguyen, "Spatial variability analysis of cu content: A case study in Jiurui Copper Mining Area," International Journal of Applied Geospatial Research (IJAGR), vol. 8, pp. 81-93, 2017. Available at: https://doi.org/10.4018/ijagr.2017010105.

[26] E. R. Ziegel, "Geostatistical software library and user's guide," Technometrics, vol. 40, p. $357,1998$.

[27] A. D. Cliff and J. K. Ord, Spatial processes: Models and applications. Pion, London: Taylor \& Francis, 1981. 